\title{
Study of the Similarities in Scale Models of a Single-Layer Spherical Lattice Shell Structure under the Effect of Internal Explosion
}

\author{
Wenbao Wang, Xuanneng Gao, and Lihui Le \\ College of Civil Engineering, Huaqiao University, Xiamen 361021, China \\ Correspondence should be addressed to Xuanneng Gao; gaoxn117@sina.com
}

Received 5 November 2016; Revised 1 January 2017; Accepted 28 February 2017; Published 16 March 2017

Academic Editor: Isabelle Sochet

Copyright (C) 2017 Wenbao Wang et al. This is an open access article distributed under the Creative Commons Attribution License, which permits unrestricted use, distribution, and reproduction in any medium, provided the original work is properly cited.

\begin{abstract}
The similarity of each scale model is verified based on the theory of similarity, deriving the similarity law of internal explosions in a single-layer spherical lattice shell structure via dimensional theory, calculated based on models with scaling coefficients of 1 , $0.8,0.6,0.4,0.2$, and 0.1 . The results show that the shock wave propagation characteristics, the distribution of the overpressure on the inner surface, the maximum dynamic response position, and the position at which the earliest explosion venting occurs are all similar to those of the original model. With the decrease of scaling coefficients, the overpressure peak value of the shock waves of each scale model, and the specific action time of the positive pressure zone, as well as specific impulse are increasingly deviated from the original model values; when the scaling coefficient is 0.1 , the maximum relative error between the overpressure peak value at the measurement point and the specific action time of the positive pressure zone as well as the specific impulse and the original model value is $4.9 \%$. Thus, it is feasible to forecast the internal explosion effect of the original structure size model by using the experiment results of the scale model with scaling coefficient $\lambda \geq 0.1$.
\end{abstract}

\section{Introduction}

In recent years, worldwide terrorist activities have become increasingly frequent, with an increasing number of bombing assaults. On January 24, 2016, the Moscow Airport in the Russian capital exploded under a terrorist attack; 35 people were killed and hundreds of people were injured. On March 22, 2016, an explosion occurred at the Brussels Airport in Belgium, killing 17 people. On June 28, 2016, an explosion occurred at the Turkey Ataturk International Airport, killing 41 people. It can be seen that steel structures with large space, high visitor flowrate, and significant symbolic value are more likely to become a target of explosion attack, and once subject to a terrorist attack, heavy casualties, property damage, and adverse social impacts are likely [1-3]. The explosion effect of explosives in the structure is much more complex than that of an external explosion, primarily because of the multiple reflection and diffraction phenomena that occur during the transmission of shock waves when meeting the roof, walls, and a variety of structures and constructions within the structure; such phenomena cause continuous superposition or offset of the reflected waves and incident waves in the structure, with gas flow fields within the building exhibiting irregular movement, thus making it difficult to determine the shock wave pressure field acting on the roof [4-6]. Therefore, it is necessary to conduct experimental study on the single-layer spherical lattice shell structure under the action of internal explosion; however, because of the constraints of the experimental techniques, research funds, and other conditions, it is difficult to conduct an internal explosion experiment in a full-scale model. A scale model experiment is a commonly used experimental method currently, and it is necessary to study whether the scale model experiment of a single-layer spherical lattice shell structure under the action of internal explosion will meet the similarity law and whether it will be affected by the size effect.

Currently, scholars have conducted experimental research studies on the damage in a structure or component under explosive impact. In foreign studies, Zyskowski et al. [7] studied the distribution of explosion load in structures. Ngo et al. [8] conducted a large $5000 \mathrm{~kg}$ explosion experiment in southern Australia and conducted a quantitative analysis 
of the parameters obtained. Spranghers et al. [9] studied a numerical simulation of the dynamic response of an aluminium plate under free-space explosion, conducted experimental verification, and studied the effect of different parameters on the simulation results. Remennikov and Uy [10] conducted a near-field explosion experiment. Dey and Nimje [11] conducted experimental research on a full-size sandwich panel explosion and performed numerical simulation analysis of the results. Ichino et al. [12] conducted a 1/20 scale model internal explosion experiment in an underground ammunition depot; the characteristics of the air shock waves and the ground vibration were analysed and verified via a 1/10 scale model experiment. In domestic research, Yang et al. $[13,14]$ simulated the shock waves propagation law of an internal explosion in closedwall vault tunnel operation via a numerical computation method and determined the propagation law of an air shock wave along the tunnel and obtained the formulas of the shock wave overpressure and action time in the tunnel; the calculated results were found to be in good agreement with the experimental results. Wei et al. [15] studied the load law of an internal explosion experiment by establishing a small volume simplified chamber. Fan et al. [16] fitted out the forecast formula of the explosive shock waves characteristic parameters of the centre of the inner structure through numerical simulation and analysis under the same working conditions as those in a straight tunnel explosion experiment. Cheng et al. [17] conducted theoretical analysis and experimental study of the large plastic deformation response of rectangular steel plates with four-sided restraints under explosive shock waves; the theoretical calculations were compared with the experimental results and the numerical calculations, revealing that the elastic-plastic analysis method had better calculation accuracy and applicability. Gao et al. $[1,4,18,19]$ conducted a series of studies on the shock wave propagation characteristics, the distribution of the pressure field, the structural dynamic response, and the explosion venting measures under internal explosion of large-space cylindrical reticulated shells, spherical reticulated shells, and other structures; the effect of various parameters, such as structure height, span, structure-to-span ratio, TNT equivalent weight, location of explosion, and hole arrangement on the explosion, was studied. Experimental researches on destruction of structures or components under explosion have gained some achievements. However, there are few studies on destruction under explosion in large-space steel structures, and, limited by such constraints as experimental techniques and scientific research funds, it is much hard to carry out an explosion experiment in full-scale model. Therefore, it is necessary to make a similarity research for scaled model experiment.

In this paper, we derived the similarity law of an internal explosion in a single-layer spherical lattice shell structure by using dimensional theory and constructed a finite element model with the scaling coefficients of $1,0.8,0.6$, $0.4,0.2$, and 0.1 based on LS-DYNA software. The shock wave propagation characteristics, the distribution law of the overpressure peak on the inner surface, the maximum

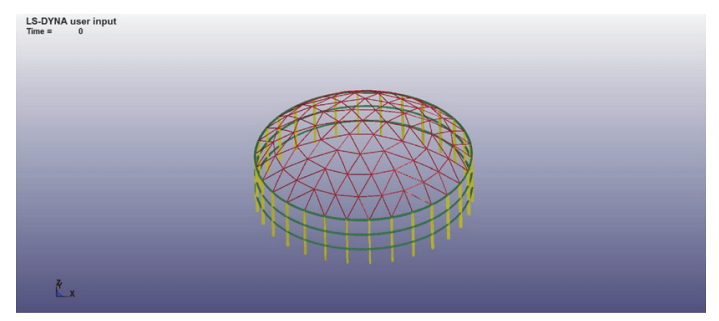

FIGURE 1: Layout of single-layer spherical shell structural elements.

dynamic response position, and the reticulated shell explosion venting phenomena of the scale models were studied. The similarity of the scale models was verified according to the critical TNT quantity of explosion venting at the connection between the wall and the reticulated shell of the model structure, providing a reference for internal explosion research.

\section{Establishment of the Finite Element Model and Selection of the Material Parameters}

\subsection{Establishment of the Finite Element Model and Selection} of Material Parameters. A K6 single-layer spherical lattice shell model was established by using ANSYS/LS-DYNA finite element software, which is mainly composed of the following: air, explosives, ground, reticulated shell bars, beams, columns, connecting structure, and envelope. The unscaled model is shown in Figure 1; the model has the following characteristics: a span of $40 \mathrm{~m}$, vector height of $8 \mathrm{~m}$, a rise span ratio of $1 / 5$, a frequency number of 5 , a lower support structure height of $10 \mathrm{~m}$, and a sectional dimension of the seamless steel tubes of the main bar, cross bar, and diagonal bar of $\varphi 140 \times 8 \mathrm{~mm}$; all the beam columns adopt the $\mathrm{H}$-section. Because the air and explosives are considered as uniform and continuous media, Solid164 is chosen as the calculation unit, and because the ground and envelope are regarded as rigid bodies, Shell163 element is adopted; Beam161 element is adopted for the structural bars, beams, and columns, and Link160 element is used for the purlin hanger. The air and explosives adopt the ALE algorithm, the air, structure, and ground use adopt the fluidsolid coupling algorithm, and the air boundary adopts the transmission boundary to avoid arithmetic errors caused by the reflection of shock waves in the air domain boundary and to improve the calculation accuracy [19]. However, when terrorist attacks and other explosions occur, the location of the explosion point is often unascertainable; considering the complexity of the explosion analysis, it is assumed that the explosion is located in the centre of the structure, $1 \mathrm{~m}$ above the ground, and the explosive charge is spherical. A finite element model with scaling coefficients of $0.8,0.6,0.4$, 0.2 , and 0.1 was established for numerical simulation and analysis.

Air uses the MAT_NULL material model, assuming that the air is the ideal gas, and the state equation adopts the EOS_LINEAR_POLYNOMIAL linear polynomial state equation [20], referring to the linear relationship between 
the air pressure and the initial internal energy, for which the expression is as follows:

$$
\begin{aligned}
& P=C_{0}+C_{1} \mu+C_{2} \mu^{2}+C_{3} \mu^{3}+\left(C_{4}+C_{5} \mu+C_{6} \mu^{2}\right) E . \\
& \mu=\frac{\rho}{\rho_{0}}-1
\end{aligned}
$$

$\rho$ is the current air density, $\rho_{0}$ is the reference air density, $E$ is the internal energy per unit of reference volume air, $V_{0}$ is the initial relative volume, the specific input parameter $\rho=$ $1.290 \mathrm{~kg} / \mathrm{m}^{3}, E_{0}=2.5 \times 10^{5} \mathrm{~J} / \mathrm{m}^{3}$, real constants $C_{0}=C_{1}=$ $C_{2}=C_{3}=C_{6}=0$, and $C_{4}=C_{5}=0.4$.

The explosive adopts the MAT_HIGH_EXPLOSIVE_ BURN high explosive material model and the JWL state equation [21], and the explosive charge is spherical, as specified with the LS-DYNA initial volume fraction keyword *INITIAL_VOLUME_FRACTION_GEOMETRY [22].

$$
\begin{aligned}
p= & A\left(1-\frac{\omega}{R_{1} V}\right) e^{-R_{1} V}+B\left(1-\frac{\omega}{R_{2} V}\right) e^{-R_{2} V} \\
& +\frac{\omega E_{0}}{V}
\end{aligned}
$$

where $A=540.9 \mathrm{GP}, B=9.4 \mathrm{GP}, R_{1}=4.5, R_{2}=1.1, \Omega=$ 0.35 , the initial internal energy $E_{0}=8 \times 10^{9} \mathrm{~J} / \mathrm{m}^{3}$, and the initial relative volume $V_{0}=1.0$.

The steel used in the entire reticulated shell structure is Q235, and the Johnson-Cook constitutive relation and failure criterion calibrated by the test group as per the test results are taken as the material model. The specific parameters are shown in Table 1.

2.2. Model Credibility Verification. The rationality of the model and material parameters is directly related to the accuracy of the model calculation; hence, it is necessary to validate the rationality of the model and the material parameters. The research group established a free-space explosion model and extracted the simulation results of the overpressure peak value at the measurement point of the shock waves and then compared the values with those of the commonly used free-space explosion overpressure empirical formula $[23,24]$; the results show that the simulation result of the overpressure peak value at the measurement point of the shock waves is consistent with the variation trend of the empirical formula result and is most similar to the calculated result of Henrych's empirical formula [24]. Thus, we can see that the calculation model and parameter values are reasonable and the calculation result of the model is credible [6].

\section{Analysis of Similar Models under Internal Explosion in Single-Layer Spherical Reticulated Shell Structure}

3.1. Similarity Theory Analysis of the Internal Explosion Scale Model of a Single-Layer Spherical Reticulated Shell Structure. The explosion of explosives inside a structure is often more
TABLE 1: Steel material parameters.

\begin{tabular}{lc}
\hline Parameters & Value \\
\hline$\rho_{S} / \mathrm{kg} \cdot \mathrm{m}^{-3}$ & 7850 \\
$E / \mathrm{MPa}$ & $2.1 \times 10^{5}$ \\
$\nu$ & 0.3 \\
$A / \mathrm{MPa}$ & 320.755 \\
$B / \mathrm{MPa}$ & 582.102 \\
$N$ & 0.3823 \\
$C$ & 0.02548 \\
$F S$ & 0.25 \\
\hline
\end{tabular}

complicated than an explosion outside the structure, primarily because of the reflection and mutual superimposition of shock waves. The internal explosion shock wave of a singlelayer spherical lattice shell structure is a complex movement that integrates incidence, reflection, diffraction, aggregation, and so forth. [6], despite all this, its explosive features obey the Hopkinson-Sachs similarity law $[25,26]$ to some extent. The damage of a reticulated shell structure primarily depends on the strength of the inner surface shock waves; the three parameters describing the strength of the shock wave are the peak overpressure value, the action time of the positive pressure zone, and the impulse. The main factors affecting the strength of shock wave are as follows:

(1) Explosive parameters: the TNT quantity is $W$, the explosive density is $\rho_{T}$, the unit mass release energy is $E_{T}$, and the explosion product expansion coefficient is $\gamma_{T}$

(2) Air parameters: the initial pressure is $p_{0}$, the initial density is $\rho_{A}$, and the adiabatic index is $\gamma_{A}$

(3) Structural parameters: the span is $l$, the vector height is $f$, the wall height is $h$, the strength is $\sigma$, Young's modulus is $E$, and the material density is $\rho$

(4) The distance $R$ between the structural surface and the explosion centre

As per $\pi$ theory of Buckingham [27, 28], the functional relationship between the shock wave overpressure on the inner surface and the influencing factors of an internal explosion of reticulated shell structure is

$$
\Delta P=f\left(W, \rho_{T}, E_{T}, \gamma_{T}, p_{0}, \rho_{A}, \gamma_{A}, l, f, h, \sigma, E, \rho, R\right)
$$

Regarding a scale model, if the structural material is the same as the prototype, then Young's modulus $E$ is not an independent quantity and can be omitted; $\gamma_{T}$ and $\gamma_{A}$ are dimensionless quantities (consistent with the dimensionless principle of the similarity law) and can also be omitted. Therefore, formula (3) can be simplified as follows:

$$
\Delta P=f\left(W, \rho_{T}, E_{T}, p_{0}, \rho_{A}, l, f, h, \sigma, \rho, R\right)
$$


Based on the principle of dimensional harmony, the relationship between the overpressure peak of the shock waves and the influencing factors is established:

$[\Delta P]$

$$
=\left[W^{a} \cdot \rho_{T}^{b} \cdot E_{T}^{c} \cdot p_{0}^{d} \cdot \rho_{A}^{e} \cdot l^{f} \cdot f^{g} \cdot h^{h} \cdot \sigma^{i} \cdot \rho^{j} \cdot R^{k}\right] .
$$

With $W, \rho_{T}$, and $E_{T}$ as the basic quantity, there is

$$
\begin{aligned}
& a=-\frac{1}{3}(f+g+h+k), \\
& b=1-d-e+\frac{1}{3}(f+g+h+k)-i-j, \\
& c=1-d-i
\end{aligned}
$$

therefore,

$$
\begin{gathered}
{[\Delta P]=\left(\rho_{T} E_{T}\right) \cdot\left(\rho_{T}^{-1} E_{T}^{-1} p_{0}\right)^{d} \cdot\left(\rho_{T}^{-1} \rho_{A}\right)^{e}} \\
\cdot\left(W^{-1 / 3} \rho_{T}^{1 / 3} l\right)^{f} \cdot\left(W^{-1 / 3} \rho_{T}^{1 / 3} f\right)^{g} \cdot\left(W^{-1 / 3} \rho_{T}^{1 / 3} h\right)^{h} \\
\cdot\left(\rho_{T}^{-1} E_{T}^{-1} \sigma\right)^{i} \cdot\left(\rho_{T}^{-1} \rho\right)^{j} \cdot\left(W^{-1 / 3} \rho_{T}^{1 / 3} R\right)^{k} \\
\frac{\Delta P}{\rho_{T} E_{T}}=f\left[\frac{p_{0}}{\rho_{T} E_{T}}, \frac{\rho_{A}}{\rho_{T}}, \frac{l}{\left(W / \rho_{T}\right)^{1 / 3}}, \frac{f}{\left(W / \rho_{T}\right)^{1 / 3}},\right. \\
\left.\frac{h}{\left(W / \rho_{T}\right)^{1 / 3}}, \frac{\sigma}{\rho_{T} E_{T}}, \frac{\rho}{\rho_{T}}, \frac{R}{\left(W / \rho_{T}\right)^{1 / 3}}\right] .
\end{gathered}
$$

The same type of charge is adopted under the same air conditions, and the structural materials remain unchanged. When $W_{P}^{1 / 3} / W_{m}^{1 / 3}=l_{p} / l_{m}=f_{p} / f_{m}=h_{p} / h_{m}=R_{p} / R_{m}=$ $1 / \lambda$, as per the law of copying proportion, $\Delta P_{p}=\Delta P_{m}$, where the subscript $p$ indicates the prototype, $m$ indicates the scale model, and $\lambda$ indicates the scaling coefficient.

Similarly, the shock wave impulse $i$ on the inner surface in a reticulated shell structure internal explosion satisfies the similarity law of

$$
\begin{gathered}
\frac{i}{W^{1 / 3} \rho_{T}^{2 / 3} E_{T}^{1 / 2}}=f\left[\frac{p_{0}}{\rho_{T} E_{T}}, \frac{\rho_{a}}{\rho_{T}}, \frac{l}{\left(W / \rho_{T}\right)^{1 / 3}}, \frac{f}{\left(W / \rho_{T}\right)^{1 / 3}},\right. \\
\left.\frac{h}{\left(W / \rho_{T}\right)^{1 / 3}}, \frac{\sigma}{\rho_{T} E_{T}}, \frac{\rho}{\rho_{T}}, \frac{R}{\left(W / \rho_{T}\right)^{1 / 3}}\right] .
\end{gathered}
$$

The same type of charge is adopted under the same air conditions, and structural materials remain unchanged. When $W_{P}^{1 / 3} / W_{m}^{1 / 3}=l_{p} / l_{m}=f_{p} / f_{m}=h_{p} / h_{m}=R_{p} / R_{m}=$ $1 / \lambda$, as per the law of copying proportion, $i_{p} / i_{m}=W_{p}^{1 / 3} /$ $W_{m}^{1 / 3}=1 / \lambda$.

$$
\text { Similarly, } T_{p}^{+} / T_{m}^{+}=W_{p}^{1 / 3} / W_{m}^{1 / 3}=1 / \lambda \text {. }
$$

3.2. Analysis of Similarity Law under Internal Explosion in Single-Layer Spherical Reticulated Shell Structure. The explosive similarity law proposed by Hopkinson [25] points out

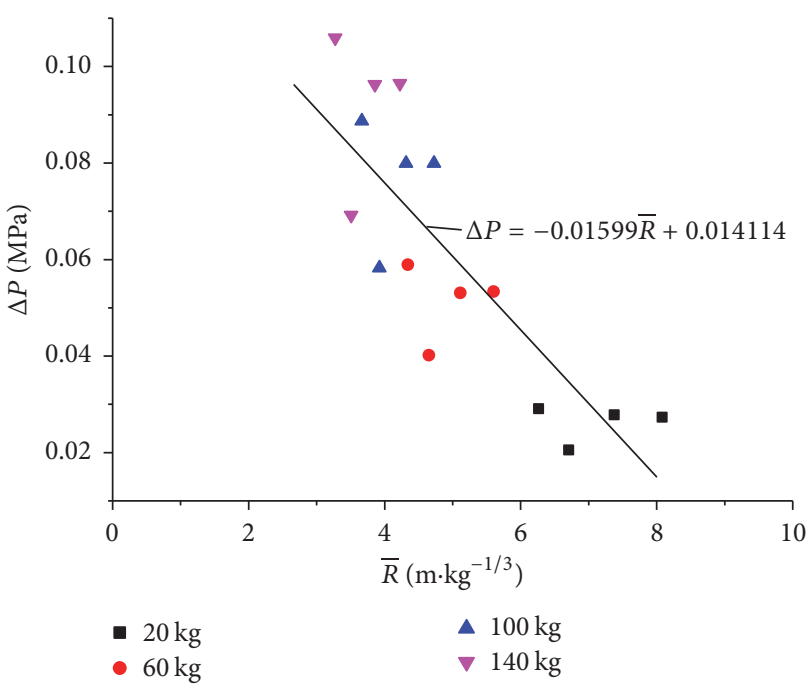

FIGURE 2: Relationship between reflection overpressure and scaled distance of typical measuring points.

that if the scaled distances $\left(R / W^{1 / 3}\right)$ are equal in condensed explosives of the same type, their pressure values of explosive wave with equal initial pressure would be equivalent. Literature [6] shows that shock waves may focus on the internal surface of spherical reticulated shell under internal explosion, so positions 1, 5, 11, and 19 in Figure 3 were selected as typical measuring points to verify whether the explosion satisfies the similarity law when explosive charge changes and structure size remains unchanged. Samples with TNT amount of $20 \mathrm{~kg}$, $60 \mathrm{~kg}, 100 \mathrm{~kg}$, and $140 \mathrm{~kg}$ were selected to form the diagram clarifying the relationship between reflection overpressure and scaled distance of typical measuring points, that is, Figure 2. As shown in Figure 2, the reflection overpressure of measuring points generally follows the similarity law if TNT amount is below the mass of structural explosion venting. Reflection overpressure has linear relationship with scaled distance and their fitting formula is

$$
\Delta P=-0.01599 \bar{R}+0.014114 \text {. }
$$

In the formula, $\Delta P$ is the reflection overpressure $(\mathrm{MPa})$ and $\bar{R}$ is the scaled distance $\left(\mathrm{m} \cdot \mathrm{kg}^{-1 / 3}\right)$.

\section{Similarity Analysis of the Internal Explosion Scale Model of the Single-Layer Spherical Reticulated Shell Structure}

4.1. Similarity Analysis of Shock Wave Propagation Characteristics. The internal explosion in reticulated shell structure is often more complicated than outside the structure [29]; when the centre explodes, the shock waves will converge on the top of the reticulated shell and the connection of the wall and the reticulated shell and finally converge at the midpoint of the ground, forming a new round of reflection and convergence [6]. The whole-process shock wave overpressure nephogram with model scaling coefficients of $1,0.8,0.6,0.4,0.2$, and 0.1 is shown in Figure 3. 

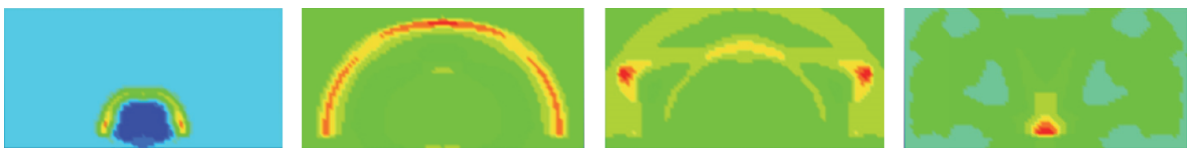

(a) $\lambda=1$
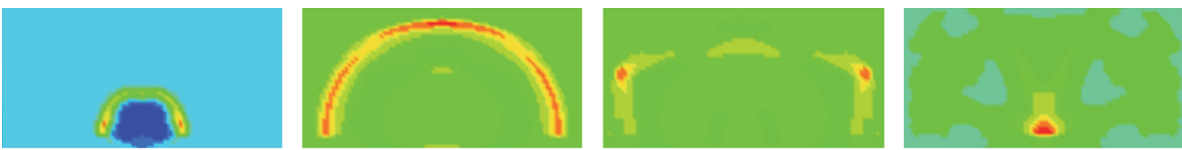

(b) $\lambda=0.8$
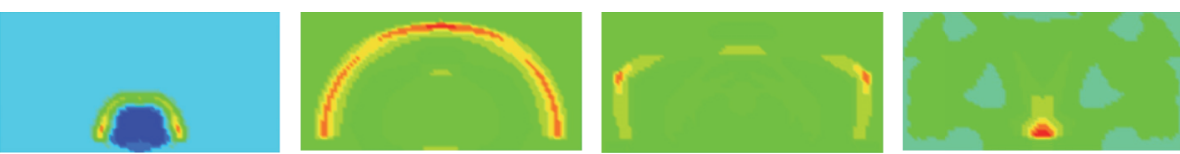

(c) $\lambda=0.6$
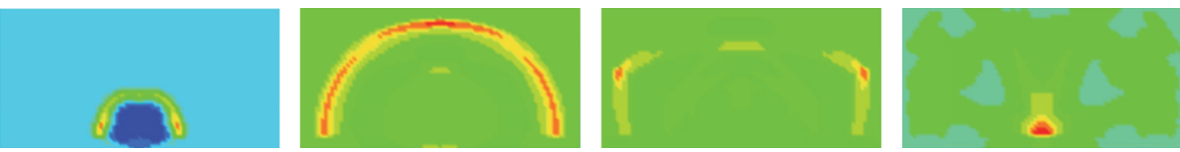

(d) $\lambda=0.4$
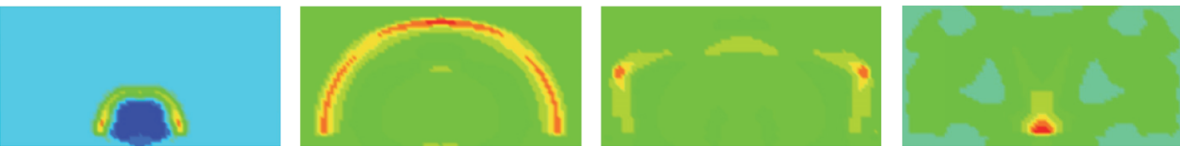

(e) $\lambda=0.2$
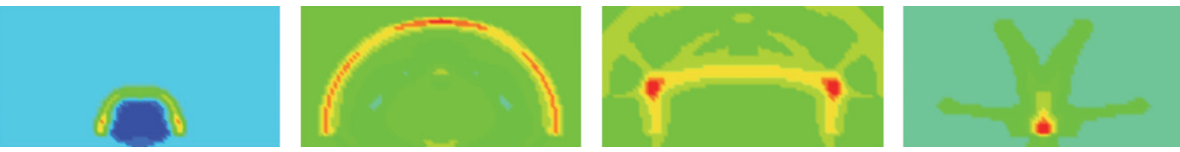

(f) $\lambda=0.1$

FIGURE 3: Shock wave overpressure nephogram of each scale model.

As shown in Figure 3, the whole-process shock wave overpressure nephogram of each scale model has the same variation trend. The shock wave propagation characteristics are as follows: an obvious Mach-wave effect occurs near the ground [30] after explosive detonation, and, with the continuation of shock wave propagation, it first reaches the top of reticulated shell and then converges on the top of the reticulated shell and the connection of the wall and the reticulated shell before finally converging at the midpoint of the ground. After the ground reflection, it has a second contact with the top of the reticulated shell, starting a new round of reflection and convergence $[6,31]$; as a result, the shock wave propagation characteristics of the scale model are similar to the original model. The source model in this paper refers to the model with scaled coefficient $\lambda=1$.

4.2. Similarity Analysis of the Distribution of Overpressure on the Inner Surface. To study the distribution characteristics of the overpressure peak value of shock waves on the internal surface of the internal explosion in a reticulated shell structure, the unit overpressure at several locations on the inner surface of the structure is analysed, as shown in Figure 4.
The overpressure peak values at measure points of each scale model are shown in Table 2.

As indicated from Table 2, the overpressure peak values at the top of the reticulated shell and the connection of the wall and the reticulated shell as well as the bottom of the wall of each scale model are larger than those of other parts. Figure 5 shows that the distribution characteristics of the unit overpressure peak values of each scale model are as follows: the distribution of overpressure peak values of the shock waves in the reticulated shell and the side wall is large on both ends and small in the middle, indicating that the distribution of the peak surface unit overpressure values of each scale model is similar to the original model.

4.3. Similarity Analysis of the Dynamic Response of the Reticulated Shell Structure. The nodal displacement and member bar stress are chosen as the dynamic response parameters [19] of the single-layer spherical lattice shell structure under the effect of internal explosion, and the maximum displacement and maximum stress response of each scale model are shown in Table 3. Table 3 indicates that the maximum displacement response of each scale model under the effect of the internal explosion occurs at the centre node 


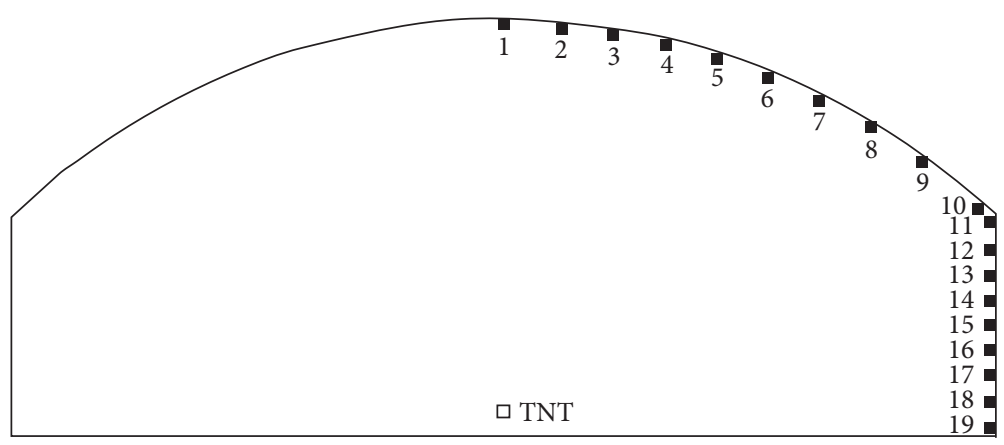

FIGURE 4: Schematic diagram of the unit positions.

TABLE 2: Peak overpressure values at each unit position.

\begin{tabular}{|c|c|c|c|c|c|c|}
\hline \multirow{2}{*}{ Unit position } & \multicolumn{6}{|c|}{ Peak overpressure values at each unit position } \\
\hline & $\Delta P / \mathrm{Pa}$ & $\Delta P / \mathrm{Pa}$ & $\Delta P / \mathrm{Pa}$ & $\Delta P / \mathrm{Pa}$ & $\Delta P / \mathrm{Pa}$ & $\Delta P / \mathrm{Pa}$ \\
\hline 1 & 105910 & 106130 & 106580 & 107500 & 106010 & 126860 \\
\hline 2 & 71480 & 71440 & 71280 & 71440 & 71460 & 78910 \\
\hline 3 & 66560 & 66560 & 66230 & 66550 & 66560 & 75380 \\
\hline 4 & 69610 & 69480 & 69280 & 69520 & 69580 & 77020 \\
\hline 5 & 69210 & 69090 & 69130 & 69120 & 69120 & 76810 \\
\hline 6 & 71510 & 71440 & 71410 & 71450 & 71450 & 79510 \\
\hline 7 & 75070 & 74710 & 74710 & 74760 & 74780 & 83250 \\
\hline 8 & 74180 & 74100 & 74000 & 74080 & 74080 & 81400 \\
\hline 9 & 73950 & 73930 & 73700 & 73950 & 73930 & 83210 \\
\hline 10 & 82960 & 82950 & 82880 & 82930 & 82940 & 90600 \\
\hline 11 & 96500 & 96490 & 96450 & 96500 & 96500 & 107650 \\
\hline 12 & 74300 & 74280 & 74020 & 74270 & 74260 & 80890 \\
\hline 13 & 74150 & 74140 & 73890 & 74140 & 74090 & 82210 \\
\hline 14 & 79120 & 79110 & 78950 & 79110 & 78970 & 86830 \\
\hline 15 & 77770 & 77770 & 77500 & 77770 & 77760 & 85280 \\
\hline 16 & 80470 & 80470 & 80110 & 80470 & 80380 & 89090 \\
\hline 17 & 85630 & 85680 & 85420 & 85680 & 85700 & 94710 \\
\hline 18 & 85680 & 85690 & 85610 & 85690 & 85690 & 96780 \\
\hline 19 & 96250 & 96230 & 96000 & 96220 & 96210 & 107180 \\
\hline Scaling coefficient $\lambda$ & 1 & 0.8 & 0.6 & 0.4 & 0.2 & 0.1 \\
\hline TNT quantity/kg & 140 & 71.69 & 30.24 & 8.96 & 1.12 & 0.14 \\
\hline
\end{tabular}

of the spherical shell, and the maximum stress response occurs near the midspan member bar, indicating that the occurring location of maximum displacement response and maximum stress response of each scale model is similar to the original model. From Figures 6 and 7, we can know that time-history curves of maximum nodal displacement and maximum member stress in scaled models fail to obey the similarity law; when the scaled coefficient $\lambda \geq 0.6$, the two curves have high similarity with the source model and when the scaled coefficient $\lambda<0.6$, the similarity lowers. This is mainly because the dynamic response of latticed shell not only is related to the explosive shock wave but also depends on the material properties of the structure itself. The scaled model in this paper is not subject to full scaling but a scaled model with structural material unchanged and size changed.
4.4. Similarity Analysis of the Reticulated Shell Destruction Phenomenon. According to the design principle of "strong structure and weak envelope" [18], the explosion venting of the reticulated shell structure is primarily envelope explosion venting. We can see from the propagation characteristics of shock waves in the internal explosion in the reticulated shell structure and the distribution characteristics of the overpressure peak values on the inner surface that the top of the reticulated shell and the connection of the wall and the reticulated shell are the key parts of explosion venting. Purlin hanger connects the maintenance structure and major structure, as shown in Figure 8; thus, purlin hanger fracture is defined as explosion venting in maintenance structure, as shown in Figure 9. To study the critical position of explosion venting in the internal explosion in the reticulated shell structure, an explosion venting simulation is conducted for 
TABLE 3: Maximum dynamic response positions of each scale model.

\begin{tabular}{lcccccc}
\hline \multirow{2}{*}{ Scaling coefficient $\lambda$} & \multicolumn{3}{c}{ Maximum displacement response } & \multicolumn{3}{c}{ Maximum stress response } \\
& $W_{\max } / \mathrm{mm}$ & $t_{1} / \mathrm{s}$ & Node position & $\sigma_{\max } / \mathrm{MPa}$ & $t_{2} / \mathrm{s}$ & Member bar position \\
\hline 1 & 140.6 & 0.126 & Midspan & 418 & 0.119 & Near the midspan \\
0.8 & 100 & 0.102 & Midspan & 416 & 0.096 & Near the midspan \\
0.6 & 62 & 0.082 & Midspan & 411 & 0.074 & Near the midspan \\
0.4 & 26 & 0.058 & Midspan & 403 & 0.051 & Near the midspan \\
0.2 & 13 & 0.023 & Midspan & 384 & 0.016 & Near the midspan \\
0.1 & 5.2 & 0.015 & Midspan & 377 & 0.018 & Near the midspan \\
\hline
\end{tabular}

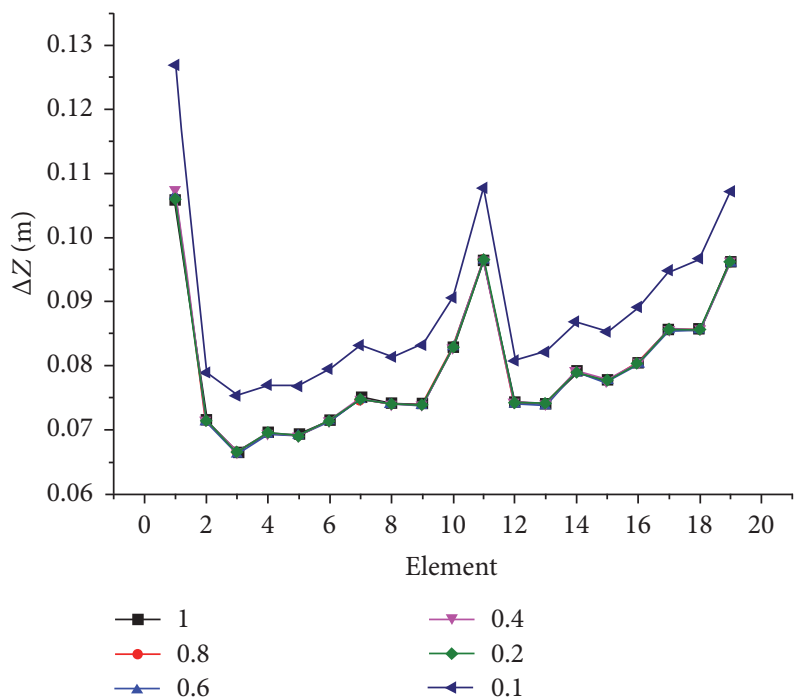

FIgURE 5: The surface unit peak overpressure values in the reticulated shell structure.

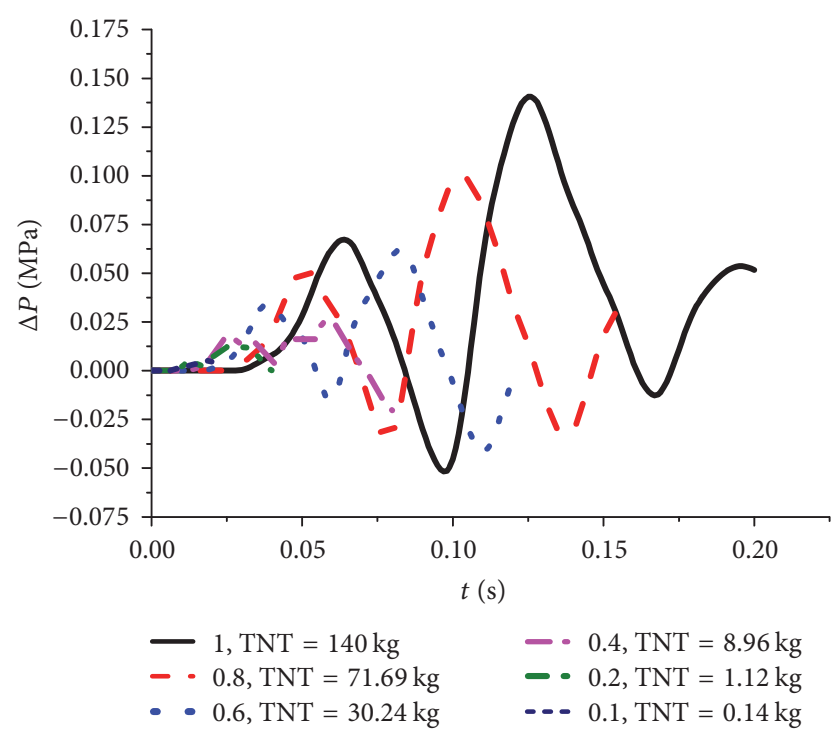

FIGURE 6: Time-history curve of maximum nodal displacement in scaled models.

each scale model. The TNT quantities and positions of each scale model in explosion venting are shown in Figure 10.

As shown in Figure 10, the explosion venting of each scale model occurs first at the connection of the wall and

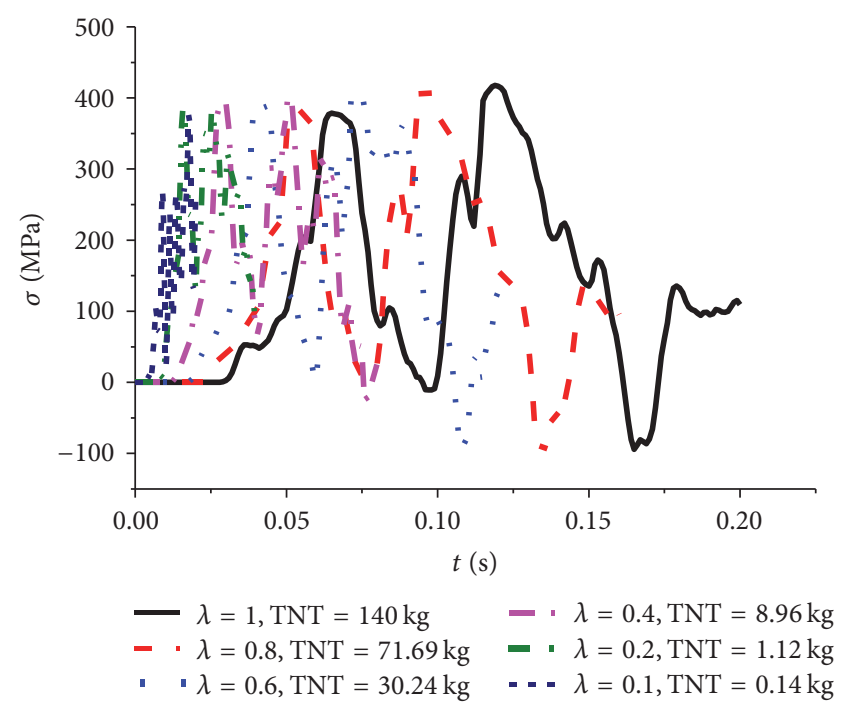

FIgURE 7: Time-history curve of maximum member stress in scaled models.

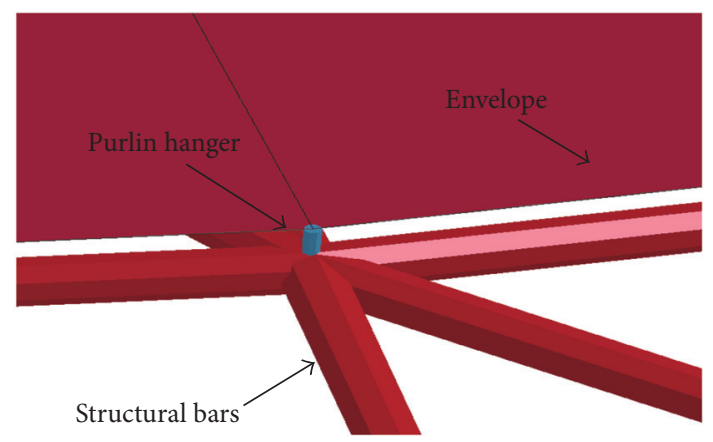

FIGURE 8: Schematic diagram of connecting component.

the reticulated shell. As the TNT quantity increases, explosion venting also occurs at the top of the reticulated shell structure. The research group has made an internal explosion experiment in scaled model with single-layer spherical lattice shell structure in the field. Experimental model and site are shown in Figure 11, wherein the lattice shell rise is $0.8 \mathrm{~m}$, span is $4 \mathrm{~m}$, rise span ratio is $1 / 5$, frequency is 4 -ring, and the height of lower supporting structure is $1 \mathrm{~m}$. Purlin hanger connects the maintenance structure and lattice shell structure of experimental model, as shown in Figure 12. The first suffered position is the joint of wall and lattice shell in 


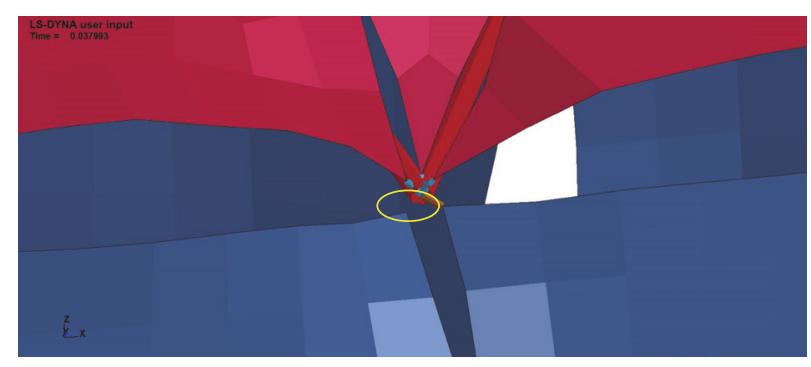

FIGURE 9: Fracture of connecting component.

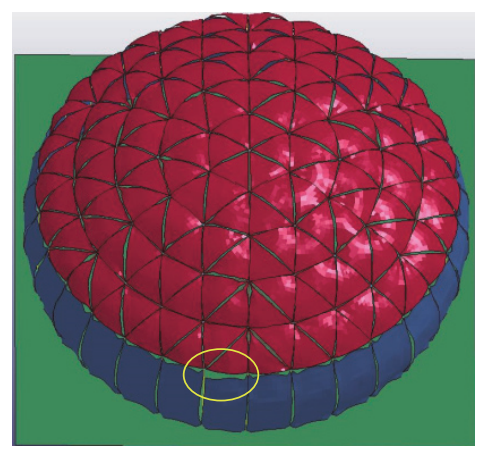

$\lambda=1, \mathrm{TNT}=160 \mathrm{Kg}$

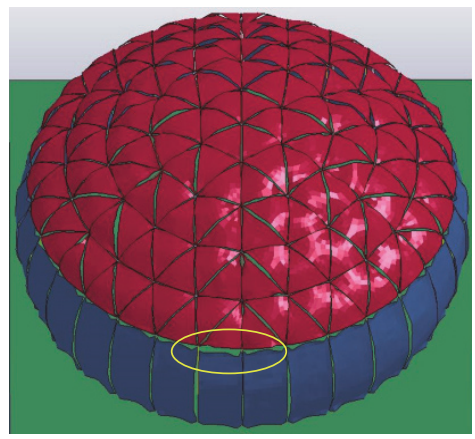

$\lambda=0.4, \mathrm{TNT}=10.24 \mathrm{Kg}$

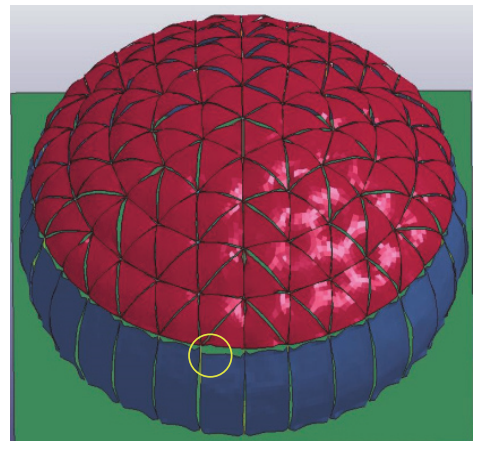

$\lambda=0.8, \mathrm{TNT}=81.93 \mathrm{Kg}$

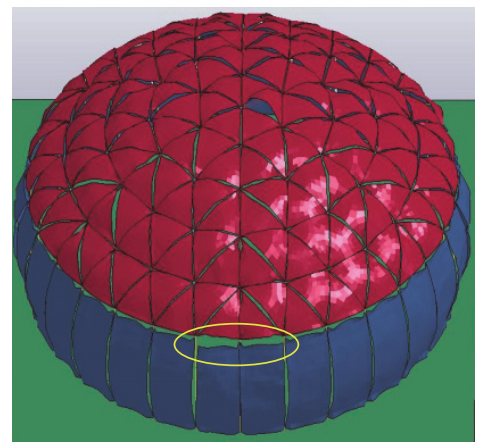

$\lambda=0.2, \mathrm{TNT}=1.28 \mathrm{Kg}$

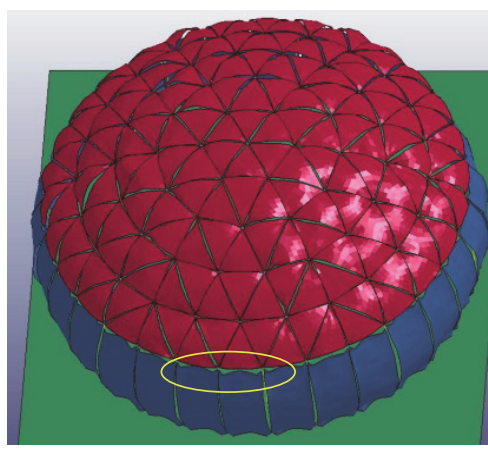

$\lambda=0.6, \mathrm{TNT}=34.56 \mathrm{Kg}$

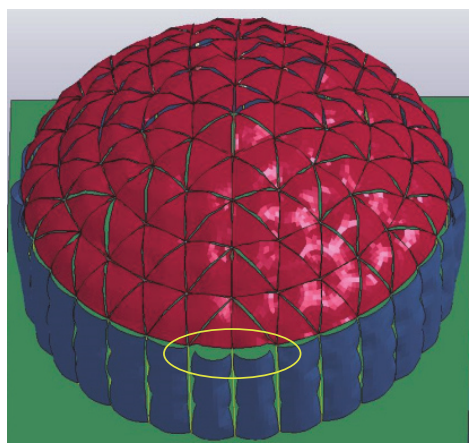

$\lambda=0.1, \mathrm{TNT}=0.15 \mathrm{Kg}$

FIGURE 10: Explosion venting positions of the envelope.
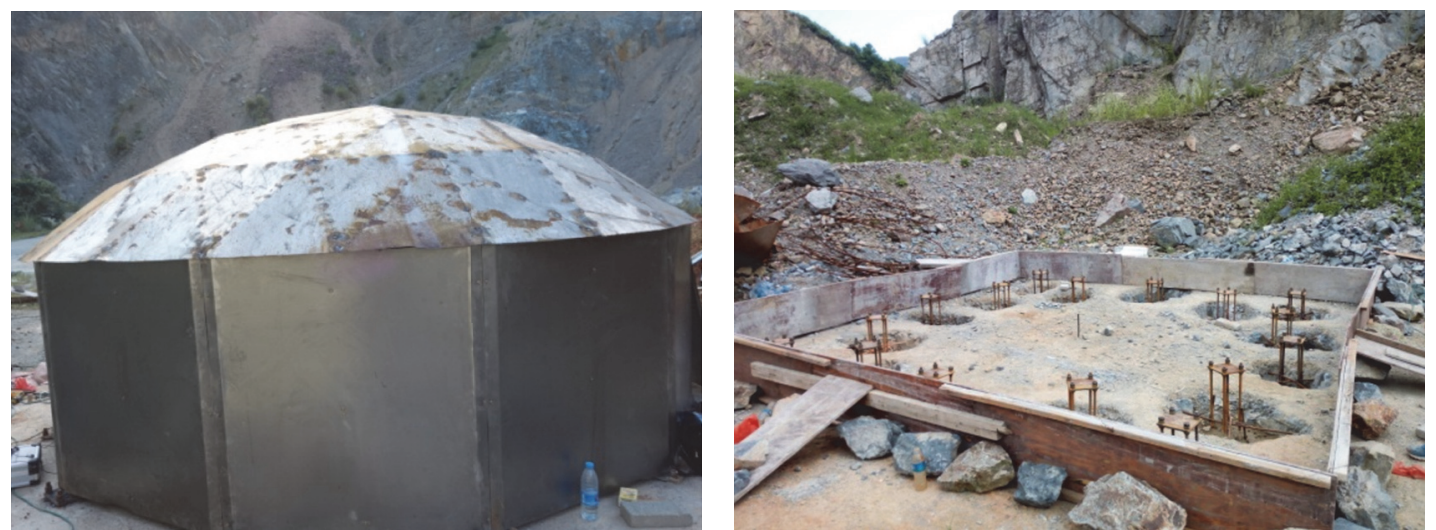

FIGURE 11: Diagram of experimental model and site. 
TABLE 4: Peak overpressure values at each unit position, action time of the positive pressure zone, and impulse.

\begin{tabular}{|c|c|c|c|c|c|c|c|c|c|c|c|c|}
\hline \multirow{2}{*}{$\lambda$} & \multicolumn{4}{|c|}{$\begin{array}{l}\text { Overpressure peak values of the } \\
\text { shock wave, } \Delta P / \mathrm{Pa}\end{array}$} & \multicolumn{4}{|c|}{$\begin{array}{c}\text { Action time of the positive pressure } \\
\text { zone, } T^{+} / \mathrm{ms}\end{array}$} & \multicolumn{4}{|c|}{ Impulse, $i / \mathrm{Pa} \cdot \mathrm{ms}$} \\
\hline & 1 & 5 & 11 & 19 & 1 & 5 & 11 & 19 & 1 & 5 & 11 & 19 \\
\hline 1 & 131712 & 83416 & 118545 & 118901 & 37.02 & 19.03 & 20.12 & 15.97 & 1007019 & 595442 & 828065 & 770899 \\
\hline 0.8 & 133139 & 83276 & 118520 & 118869 & 29.63 & 15.21 & 16.07 & 12.80 & 804899 & 475771 & 662355 & 618396 \\
\hline 0.6 & 133413 & 83368 & 118214 & 118722 & 22.17 & 11.38 & 11.92 & 9.62 & 606907 & 355934 & 495916 & 462884 \\
\hline 0.4 & 134818 & 83306 & 118529 & 118863 & 14.82 & 7.59 & 7.96 & 6.37 & 401788 & 237994 & 330996 & 309280 \\
\hline 0.2 & 131962 & 83307 & 118501 & 118835 & 7.39 & 3.82 & 4.03 & 3.16 & 196783 & 119139 & 165342 & 154784 \\
\hline 0.1 & 143020 & 81774 & 117695 & 119148 & 3.65 & 1.85 & 1.97 & 1.52 & 98776 & 59533 & 81695 & 76120 \\
\hline
\end{tabular}

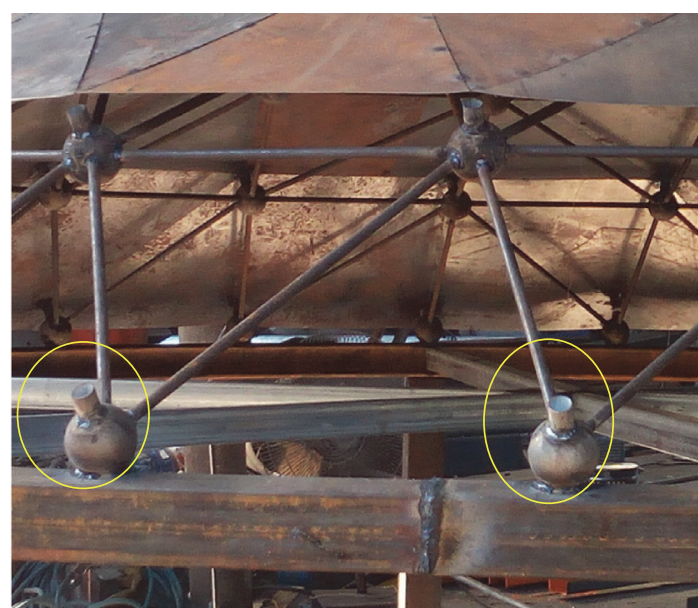

Figure 12: Connection by purlin hanger.

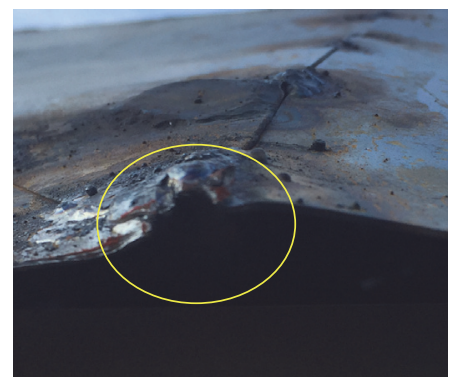

FIGURE 13: First explosion venting position in experimental model.

field experiment, as shown in Figure 13, which is consistent with the first explosion's venting position in simulated scaled models, showing similarity between explosion venting of lattice shell in scaled models and that in original model.

4.5. Similarity Verification of the Scale Models. The destruction of the reticulated shell envelope mainly depends on the strength of the shock waves, and there are three parameters that describe the strength of the shock waves: overpressure peak, action time of positive pressure zone, and impulse. As mentioned above, the destruction phenomena of all scale models are similar; therefore, the critical TNT quantity undergoing explosion venting at the connection of the wall and the reticulated shell in the model structure is taken as the basis for the calculation of each scale model to analyse whether the overpressure peak value, action time of the positive pressure zone, and impulse under critical TNT quantity obey a similarity law in the scale model.

According to the propagation characteristics of the shock waves in the internal explosion in the reticulated shell structure and the distribution characteristics of the overpressure peak values on the inner surface, units 1, 5, 11, and 19 are selected as typical locations for a pressure time-history diagram analysis. The typical location pressure time-history diagram of each scale model is shown in Figure 14.

Figure 14 reveals that the variation trend of the pressure time-history curve at the measurement point locations of each scale model and that of the original model are consistent: when the scaling coefficient $\lambda \geq 0.2$, the overpressure peak value at each measure point does not change much compared with the original model value; when $\lambda=0.1$, the overpressure peak value at each measurement point is greater than that of the original model value. With the decrease of the scaling coefficient, the scale model pulse width gradually decreases. The overpressure peak value, action time of positive pressure zone, and impulse of each scale model under the critical TNT quantity are shown in Table 4.

From the above similarity theory analysis of the scale model, we can see that $\Delta P_{P}=\Delta P_{m}, i_{p} / W_{p}^{1 / 3}=i_{m} / W_{m}^{1 / 3}$, and $T_{P}^{+} / W_{p}^{1 / 3}=T_{m}^{+} / W_{m}^{1 / 3}$; to facilitate the analysis of scale model similarity, Table 4 is converted to Table 5 .

Figure 15 shows the relationship diagram between the scaling coefficients and the peak overpressure value of shock wave, specific action time of positive pressure zone, and specific impulse. As seen from Table 5 and Figure 15, (a) with the decrease of scaling coefficient $\lambda$, the deviation degree of the peak overpressure value of shock wave $P$, specific action time of positive pressure zone $T^{+} W^{-1 / 3}$, and specific impulse $i W^{-1 / 3}$ in each scale model and the original model become larger with maximum errors of $4.9 \%, 2.7 \%$, and $2.2 \%$; (b) the deviation degree of the peak overpressure value of shock waves $P$ and the original model value is less than that of the specific action time of positive pressure zone $T^{+} W^{-1 / 3}$ and specific impulse $i W^{-1 / 3}$; (c) the deviation degree of the overpressure peak value of shock waves $P$, specific action time of positive pressure zone $T^{+} W^{-1 / 3}$, and specific impulse $i W^{-1 / 3}$ of the reticulated shell top unit 1 and the original model is greater than that of other parts; (d) when scaling 

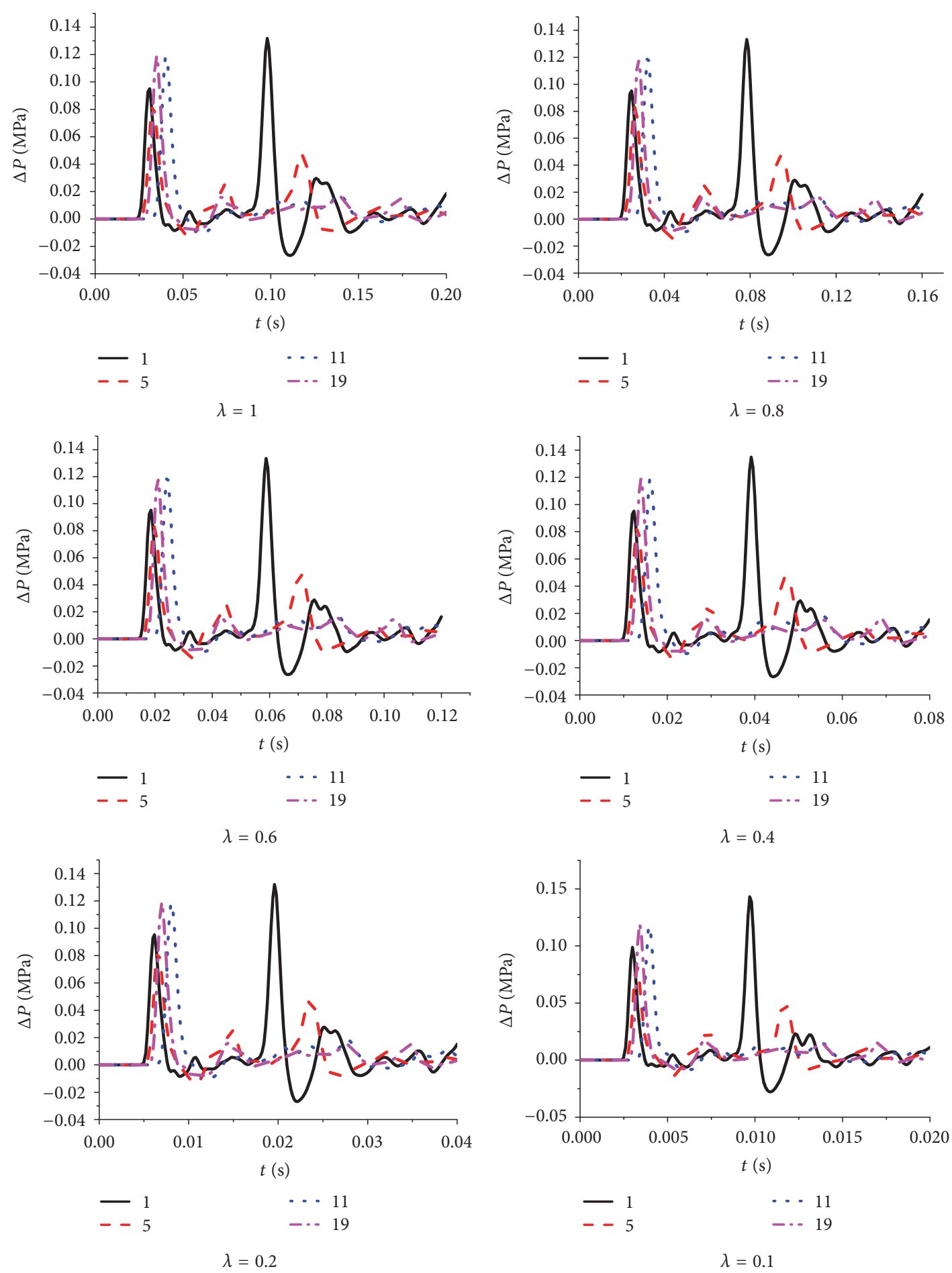

FIGURE 14: Typical location pressure time-history diagram of each scale model.

coefficient $\lambda=0.1$, the relative errors of the peak overpressure values and the original model values of units $1,5,11$, and 19 are $4.9 \%, 0.9 \%, 0.4 \%$, and $0.1 \%$, the relative errors of specific action time of positive pressure zone $T^{+} W^{-1 / 3}$ are $0.7 \%, 0.9 \%$, 0 , and $2.7 \%$, and the relative errors of specific impulse $i W^{-1 / 3}$ are $0.2 \%, 2.2 \%, 0.8 \%$, and $0.9 \%$. Below are main possible reasons: (a) as the scaled coefficient decreases, the action time in positive pressure region and specific impulse values have more errors, so their accuracy is less than that of the peak overpressure; (b) as the scaled coefficient decreases, the error of grid size effect becomes larger; (c) unit 1 on the top of lattice shell is obviously affected by the secondary wave; (d) as the model shrinks, the boundary effect on the system is obviously larger. Therefore, the peak overpressure value, the action time 
TABLE 5: Overpressure peak values at each unit position, specific action time of positive pressure zone, and specific impulse.

\begin{tabular}{|c|c|c|c|c|c|c|c|c|c|c|c|c|}
\hline \multirow[t]{2}{*}{$\lambda$} & \multicolumn{4}{|c|}{$\begin{array}{l}\text { Overpressure peak value of shock wave, } \\
\qquad \Delta \mathrm{P} / \mathrm{Pa}\end{array}$} & \multicolumn{4}{|c|}{$\begin{array}{l}\text { Specific action time of positive pressure } \\
\text { zone, } \\
\qquad T^{+} W^{-1 / 3} / \mathrm{ms} \cdot \mathrm{kg}^{-1 / 3}\end{array}$} & \multicolumn{4}{|c|}{$\begin{array}{l}\text { Specific impulse, } \\
i W^{-1 / 3} / \mathrm{Pa} \cdot \mathrm{ms}^{-\mathrm{kg}^{-1 / 3}}\end{array}$} \\
\hline & 1 & 5 & 11 & 19 & 1 & 5 & 11 & 19 & 1 & 5 & 11 & 19 \\
\hline 1 & 131712 & 83416 & 118545 & 118901 & 6.82 & 3.51 & 3.71 & 2.94 & 185495 & 109681 & 152531 & 142001 \\
\hline 0.8 & 133139 & 83276 & 118520 & 118869 & 6.82 & 3.50 & 3.70 & 2.95 & 185322 & 109543 & 152502 & 142381 \\
\hline 0.6 & 133413 & 83368 & 118214 & 118722 & 6.81 & 3.49 & 3.66 & 2.95 & 186322 & 109273 & 152248 & 142107 \\
\hline 0.4 & 134818 & 83306 & 118529 & 118863 & 6.82 & 3.50 & 3.67 & 2.93 & 185025 & 109597 & 152425 & 142425 \\
\hline 0.2 & 131962 & 83307 & 118501 & 118835 & 6.81 & 3.52 & 3.71 & 2.91 & 181239 & 109728 & 152281 & 142557 \\
\hline 0.1 & 143020 & 81774 & 117695 & 119148 & 6.87 & 3.48 & 3.71 & 2.86 & 185904 & 112045 & 153756 & 143263 \\
\hline
\end{tabular}

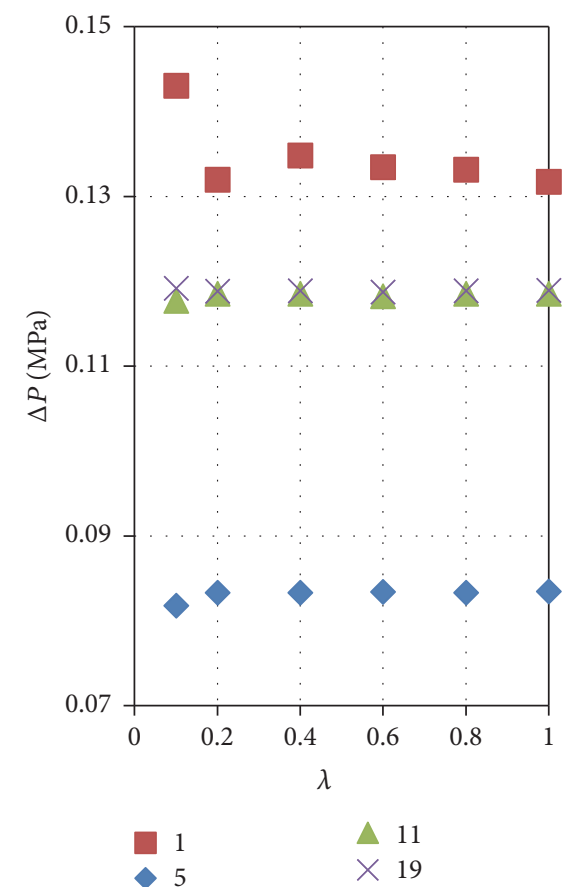

(a) Influence of $\lambda$ on $\Delta P$

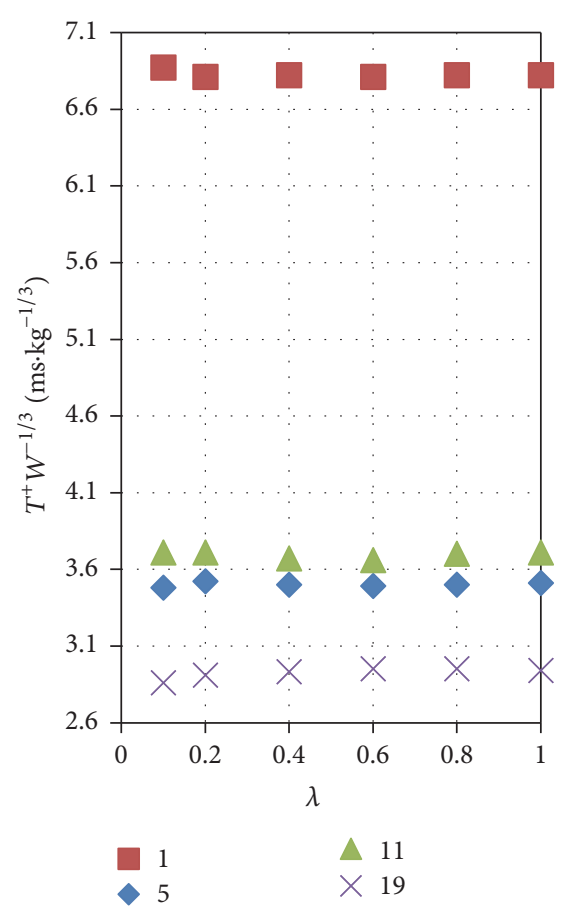

(b) Influence of $\lambda$ on $T^{+} W^{-1 / 3}$

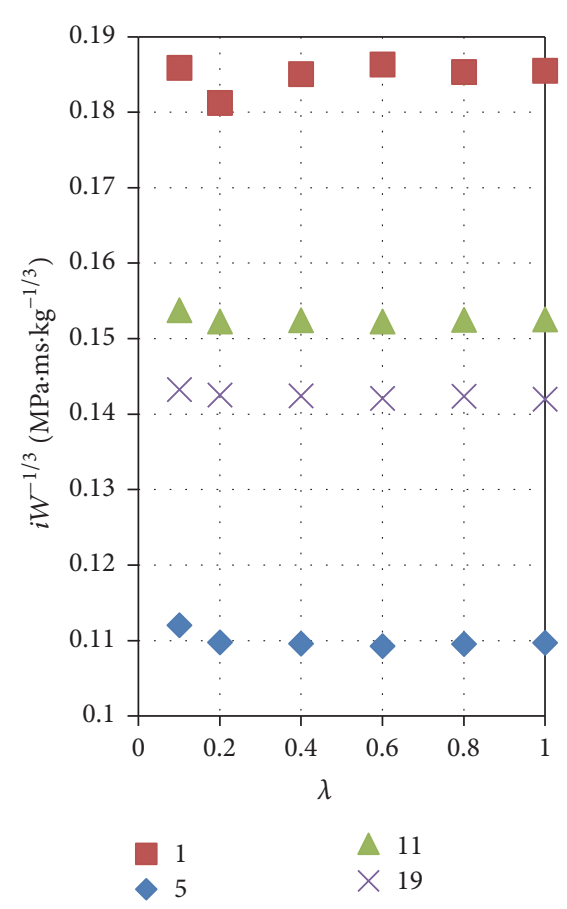

(c) Influence of $\lambda$ on $i W^{-1 / 3}$

FIGURE 15: Relationship diagram between the scaling coefficients and the overpressure peak value of the shock wave, the specific action time of positive pressure zone, and the specific impulse.

of positive pressure zone, and the impulse under the critical TNT quantity are similar in the scale models.

\section{Conclusion}

(1) The calculation model and parameter selection of the single-layer spherical internal explosion in the reticulated shell structure based on LS-DYNA are reasonable, and the results of the numerical simulation and analysis for large-space structures under internal explosion are credible.

(2) If the structure size remains unchanged and TNT quantity changes, the reflection overpressure on the inner surface of the reticulated shell is always subject to the similarity law of B. Hopkinson, and the reflection overpressure is linearly proportional to the scaled distance.

(3) If the structure material remains unchanged and size changes, the shock wave propagation characteristics and the distribution of overpressure on the inner surface of each scale model are similar to those of the original model; positions of maximum displacement response and maximum stress response in scaled models have similarity with those in the original model; time-history curves of maximum nodal displacement and maximum member stress in scaled models generally have no similarity with those in the original model and such similarity decreases with the reduction of scaled coefficient; the explosion venting of each scale model first occurs at the connection of 
wall and the reticulated shell has similarity with that in source model.

(4) Simulation and analysis of each scale model are conducted according to the critical TNT quantity of explosion venting at the connection between the wall and the reticulated shell of the model structure; the results show that the overpressure peak value of the shock waves $P$, the specific action time of the positive pressure zone $T^{+} W^{-1 / 3}$, and the specific impulse $i W^{-1 / 3}$ in each scale model are generally similar to those of the original model, and as the scaled coefficient reduces, the above three factors have larger deviation extent and lower similarity. Therefore, it is feasible to forecast the internal explosion effect of the original structure size model by adopting scaling coefficient $\lambda \geq 0.1$ in a scale model experiment.

\section{Conflicts of Interest}

The authors declare that there are no conflicts of interest regarding the publication of this article.

\section{Acknowledgments}

The authors wish to acknowledge the financial support from the Natural Science Foundation of China (no. 51278208), the Fujian Province College \& University-Industry Cooperative Major Project in Science and Technology (no. 2012Y4010), the Fujian Natural Science Foundation (no. 2011J01319), and the Postgraduate Research and Innovation Capacity Training Plan of Huaqiao University (no. 1400104003).

\section{References}

[1] X.-N. Gao, S.-P. Wang, and Y. Jiang, "Shock wave pressure distribution on large-space structures and explosion venting under blast loading," Engineering Mechanics, vol. 27, no. 4, pp. 226-233, 2010.

[2] P. F. Mlakar Sr., W. G. Corley, M. A. Sozen, and C. H. Thornton, "The Oklahoma City bombing: analysis of blast damage to the Murrah Building," Journal of Performance of Constructed Facilities, vol. 12, no. 3, pp. 113-119, 1998.

[3] N. Ishikawa and M. Beppu, "Lessons from past explosive tests on protective structures in Japan," International Journal of Impact Engineering, vol. 34, no. 9, pp. 1535-1545, 2007.

[4] G. Xuanneng, L. Ying, and W. Shupeng, "Analysis of explosive shock wave pressure distribution on large-space cylindrical reticulate shell based on LS-DYNA," Journal of Vibration and Shock, vol. 30, no. 9, pp. 70-75, 2011.

[5] X. Bai, X. Li, and Y. Yang, "Calculation model and the distribution of wave pressure under internal explosion in closed space," Explosive Materials, vol. 44, no. 3, pp. 22-26, 2015.

[6] W. Wang and X. Gao, "Propagation law of shock waves in single layer spherical lattice shell under internal explosion," Journal of Interdisciplinary Mathematics, vol. 19, no. 3, pp. 527-547, 2016.

[7] A. Zyskowski, I. Sochet, G. Mavrot, P. Bailly, and J. Renard, "Study of the explosion process in a small scale experiment-structural loading," Journal of Loss Prevention in the Process Industries, vol. 17, no. 4, pp. 291-299, 2004.
[8] T. Ngo, R. Lumantarna, A. Whittaker et al., "Quantification of the blast-loading parameters of large-scale explosions," Journal of Structural Engineering, vol. 141, no. 10, 2015.

[9] K. Spranghers, I. Vasilakos, D. Lecompte, H. Sol, and J. Vantomme, "Numerical simulation and experimental validation of the dynamic response of aluminum plates under free air explosions," International Journal of Impact Engineering, vol. 54, pp. 83-95, 2013.

[10] A. M. Remennikov and B. Uy, "Explosive testing and modelling of square tubular steel columns for near-field detonations," Journal of Constructional Steel Research, vol. 101, pp. 290-303, 2014.

[11] C. Dey and S. Nimje, "Experimental and numerical study on response of sandwich plate subjected to blast load," Experimental Techniques, vol. 40, no. 1, pp. 401-411, 2016.

[12] H. Ichino, T. Ohno, and N. Ishikawa, "Internal explosion tests for scaled subsurface magazines," International Journal of Protective Structures, vol. 7, no. 1, pp. 100-122, 2016.

[13] K.-Z. Yang and X.-M. Yang, "Shock waves propagation inside tunnels," Explosion and Shock Waves, vol. 23, no. 1, pp. 37-40, 2003.

[14] Y. Xiumin, Y. Kezhi, W. Anbao et al., "From the numerical simulation result of tunnel using wear existent necessity of inward and outward," Protective Engineering, no. 4, pp. 13-22, 2001.

[15] J.-F. Wei, W.-X. Dai, Y.-X. Xu, G.-M. Wu, X.-T. Zhou, and S.-S. Wang, "Anti-warship missile penetrating to warship and ship's inner-explosion damage," Journal of Vibration and Shock, vol. 31, no. 20, pp. 162-165, 2012.

[16] J. Fan, D.-L. Xu, and X.-J. Ren, "Propagation of shock waves in protective structures with holes under contact explosive loads," Explosion and Shock Waves, vol. 34, no. 6, pp. 658-666, 2014.

[17] Z. Cheng, K. Xiangshao, and W. Weiguo, "Elasstic-plastic dynamic response of rectangular plates subjected to blast loads," Shipbuilding of China, no. 3, pp. 19-30, 2015.

[18] X.-N. Gao, Y. Liu, and W.-Y. Yang, "Numerical simulation for damage of Ma Chang Ping highway toll station under lorryblasting," Journal of Vibration and Shock, vol. 31, no. 21, pp. 184$189,2012$.

[19] G. Xuanneng, L. Chao, and J. Yuan, "Dynamic responses of single-layer spherical steel reticulated shell under internal explosions," Journal of Tianjin University(Science and Technology), vol. S1, pp. 102-109, 2015.

[20] X.-N. Gao and Y.-J. Wu, "Numerical calculation and influence parameters for TNT explosion," Chinese Journal of Explosives \& Propellants, vol. 38, no. 3, pp. 32-39, 2015.

[21] LSTC, LS-DYNA Keyword User's Manual, Version 971, 2005.

[22] LS-DYNA, Keyword User's Manual, Livemore Software Technology Corporation, 2003.

[23] L. Yiqi and M. Suzhen, Explosive Mechanics, Science Press, Beijing, China, 1992.

[24] J. Henrych, The Dynamics of Explosion and Its Use, Elsevier Scientific Publishing Company, Amsterdam, The Netherlands, 1979.

[25] B. Hopkinson, “British ordnance board minutes," Report 13565, British Ordnance Office, London, UK, 1915.

[26] R. G. Sachs, "The dependence of blast on ambient pressure and temperature," BRL Report 466, Aberdeen Proving Ground, Aberdeen, Md, USA, 1944.

[27] E. Buckingham, "On physically similar systems; illustrations of the use of dimensional equations," Physical Review, vol. 4, no. 4, pp. 345-376, 1914. 
[28] E. Buckingham, "The principle of similitude," Nature, vol. 96, no. 2406, pp. 396-397, 1915.

[29] X.-H. Zhang, J. Wang, J.-Y. Zhao, and Y.-Y. Wu, "Blast shock wave characteristics and propagation law of internal gas explosion," Engineering Mechanics, vol. 31, supplement 1, pp. 258-264, 2014.

[30] C. Bing, Y. Zhiyong, and C. Huiwu, "An experimental investigation on the loading performance and propagation law of detonation mach-waves," Journal of Ballistic, vol. 12, no. 2, pp. 78-83, 2000.

[31] W. Yanjie and G. Xuanneng, "Numerical simulation for the explosion shock waves and correction of calculation formula of overpressure," Journal of Huaqiao University (Natural Science), vol. 35, no. 3, pp. 321-326, 2014. 


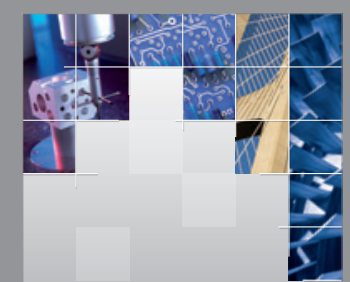

\section{Enfincering}
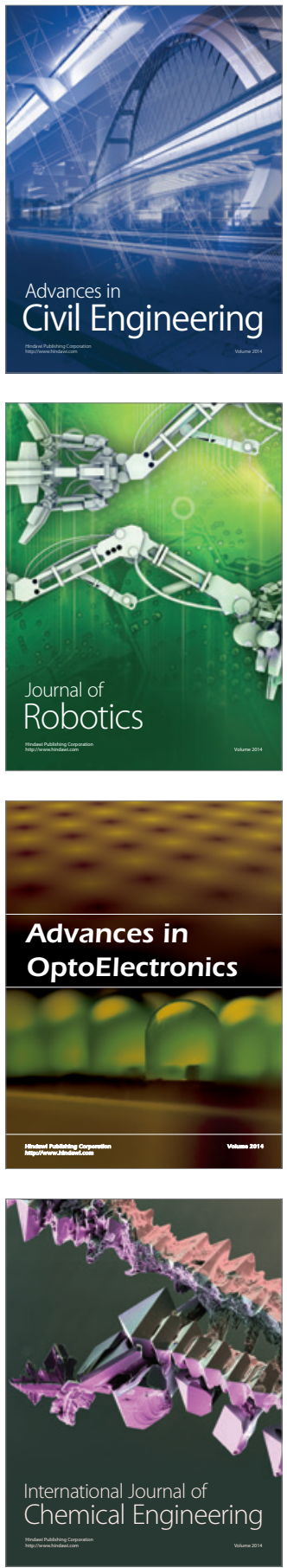

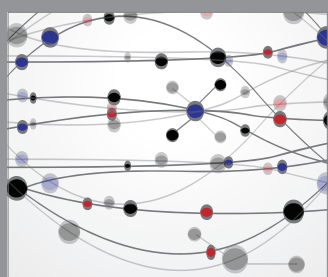

The Scientific World Journal

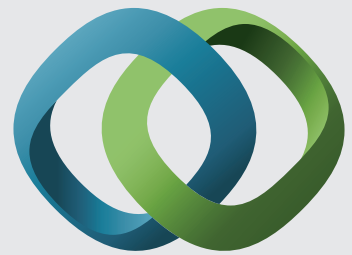

\section{Hindawi}

Submit your manuscripts at

https://www.hindawi.com
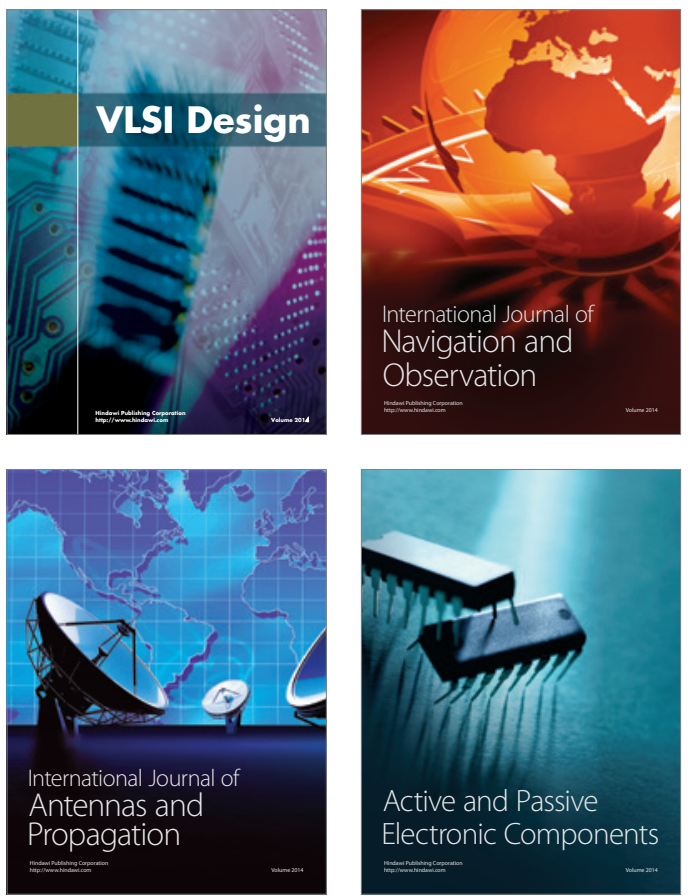
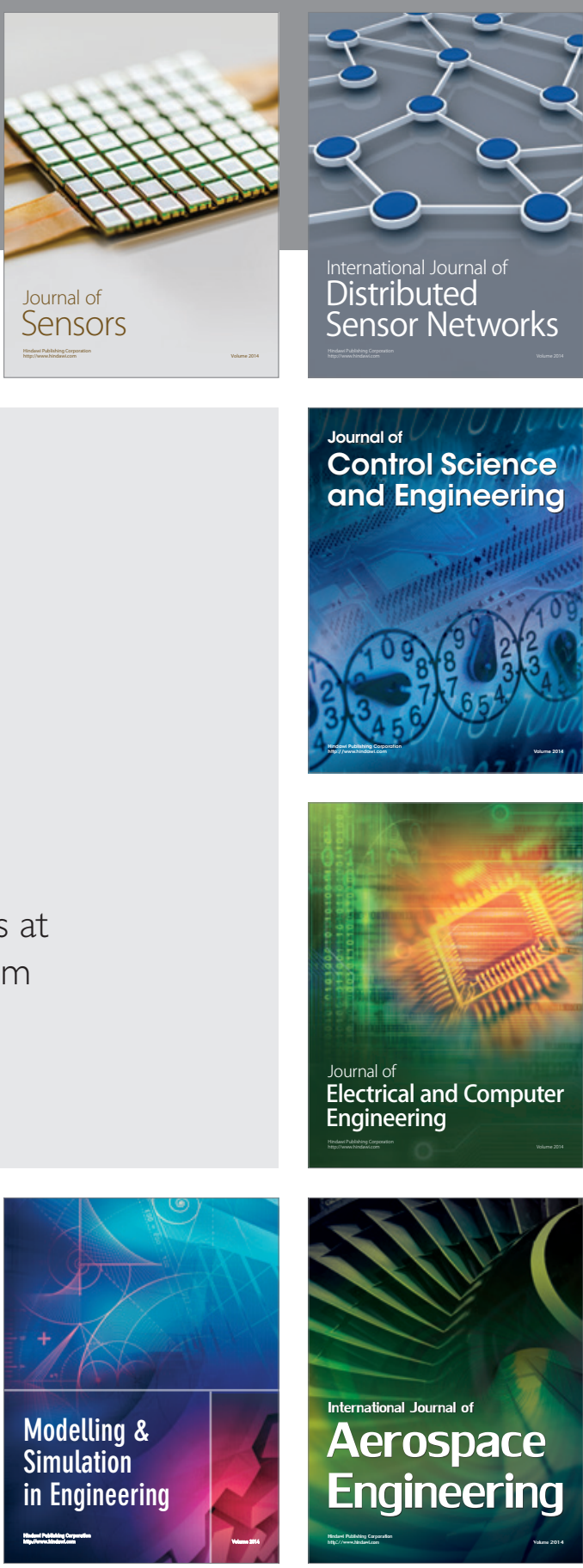

International Journal of

Distributed

Sensor Networks

$-$

Joumal of

Control Science

and Engineering
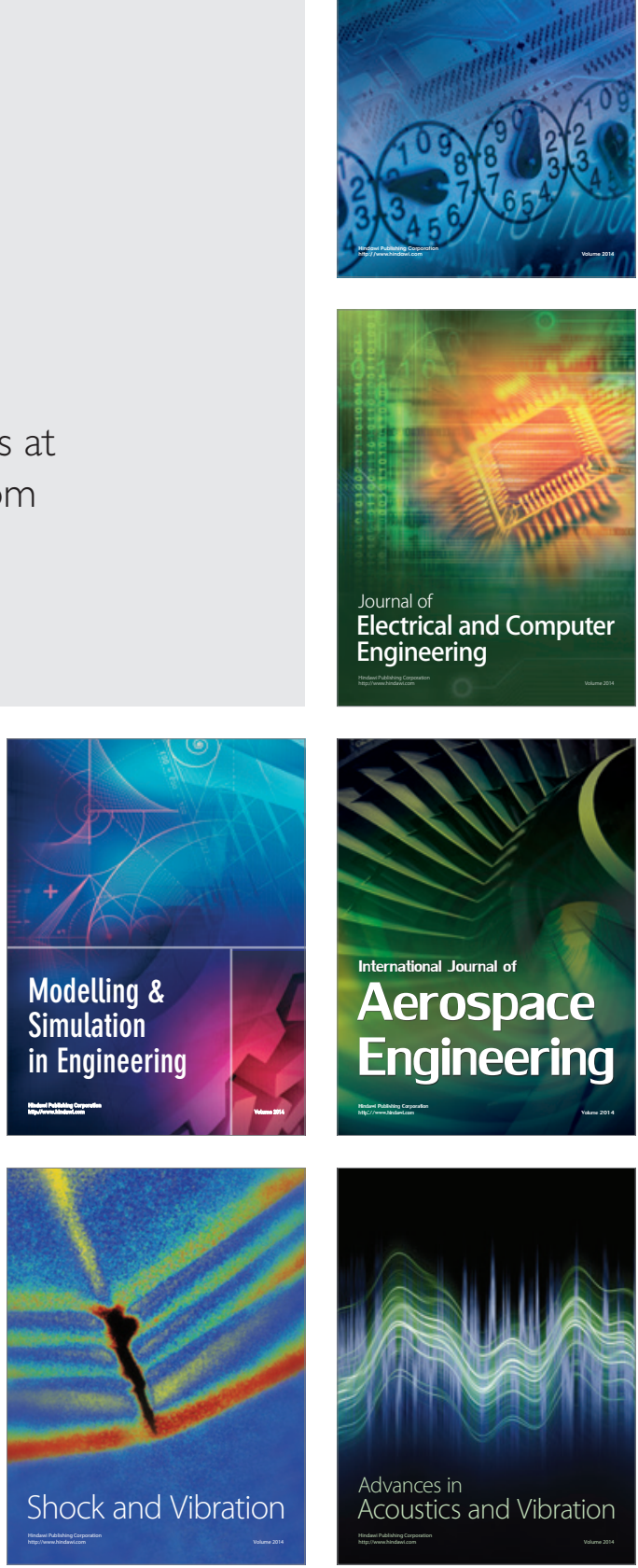